\title{
Article
}

\section{Supporting students undertaking the Specialist Practitioner Qualification in District Nursing}

Ginger, Tracey and Ritchie, Georgina Louise

Available at http://clok.uclan.ac.uk/20594/

Ginger, Tracey and Ritchie, Georgina Louise (2017) Supporting students undertaking the Specialist Practitioner Qualification in District Nursing. British Journal of Community Nursing, 22 (11). pp. 542-546. ISSN 1462-4753

It is advisable to refer to the publisher's version if you intend to cite from the work. 10.12968/bjcn.2017.22.11.542

For more information about UCLan's research in this area go to http://www.uclan.ac.uk/researchgroups/ and search for < name of research Group>.

For information about Research generally at UCLan please go to http://www.uclan.ac.uk/research/

All outputs in CLoK are protected by Intellectual Property Rights law, including Copyright law. Copyright, IPR and Moral Rights for the works on this site are retained by the individual authors and/or other copyright owners. Terms and conditions for use of this material are defined in the policies page. 


\section{Key words:}

Learning Contracts / Plans, District Nurse Education, Practice Teachers, Mentors.

\section{Key points:}

1. District Nursing is an ever evolving and challenging role; this is reflected in the complex needs of students undertaking programmes of education to register as specialist practitioners.

2. Practice Teachers and mentors must manage the demands of their own clinical and leadership roles in addition to fulfilling a pivotal role in the development of the future community nursing workforce.

3. Learning plans may play a role in facilitating a structured educational pathway for both the SPQDN student and Practice Teacher or mentor.

\section{Abstract:}

The ever-evolving role of the Specialist Practitioner Qualified District Nurse (SPQDN) presents an increasing number of challenges for Practice Teachers and mentors in preparing SPQDN students for the elevated level clinical and transformational leadership necessary to ensure high quality patient care. The daily challenges of clinical practice within the community nursing setting in addition to undertaking educational interventions in the clinical arena demand that a structured approach to supervision and mentorship is crucial. Employing learning plans to assess individual students learning needs, prepare plans for educational developments and interventions and evaluate a student's progress can be a helpful tool in aiding the learning journey for both the SPQDN student and Practice Teacher or mentor. This article examines how and why a structured learning plan may be used in supporting learning and competency in achieving the necessary level of practice to meet the requirements of the SPQDN.

The nature of District Nursing Practice is changing and education must evolve to meet this change: For nurse educators in both Higher Education Institutions (HEI's) and within the clinical practice setting knowledge and understanding of drivers within clinical practice and the influences of research, social, economic and political trends upon them is crucial in order to establish parity across the theoretical 
and practical components of nurse education and to minimise the so called 'theory - practice gap' (Bastable, 2014). Since the integration of nursing education into higher education and the subsequent move to an all degree profession within nursing, keeping abreast of the drivers within the clinical arena has become increasingly challenging yet crucial if nurse education is to remain congruent with the needs of the public and patients (Lepper, 2010). This is particularly important for those involved in post registration education and delivery of SPQDN education where the aim of education is to prepare future clinical leaders competent not only clinically but also in change management, clinical supervision and leadership of large teams (QNI, 2015a).

A key message in the paper; The Educational Outcomes Framework (Department of Health, 2013) was that the nursing profession is changing and nurse education is required to reflect this. Acknowledgment that practice must change is not new; dialogue within SPQDN education circles has for some time identified the need to support students and Practice Teachers or mentors as the role of the SPQDN has evolved (Cook, 2010). Increasingly SPQDN's are pivotal in preventing hospital admissions, facilitating early discharge, developing advanced clinical assessment, nursing diagnosis and prescribing practice as the future focus of the NHS is upon us (NHS England, 2014).

The Royal College of Nursing (2012) has encouraged evaluation of nursing education programmes. This is further endorsed by the reports of Francis (2013) and Keogh (2013) where the requirement for competent nurses to provide holistic care was identified. NHS England (2014) has highlighted that a more holistic approach to clinical practice is required; with multi-professional groups working collaboratively, breaking down boundaries so that all professional groups focus on the patient's needs. An area arguably already seen as a standard element of SPQDN practice by many.

However challenges exist; low staffing levels within the clinical arena continue to be an issue for nursing practice, and a particular shortfall in SPQDN's has been reported, while numbers of SPQDN students have seen a small increase in recent years workforce predictions indicate we are on a cliff edge due to changing demographics of the District Nursing workforce. (QNI, 2015b). This is further 
exacerbated by reducing funding for stakeholders such as Health Education England; which will effect recruitment of student nurses at pre- registration level and at post-registration level where much of the funding for continuing professional development may be lost.

\section{An introduction to plans learning:}

District Nursing requires development of both theoretical knowledge and clinical skills to ensure the safe provision of high quality care in the patient's own home. In addition, District Nurses are required to practice in adherence with the Nursing and Midwifery Council's: Standards for Specialist Education and Practice (2001). Primarily it is necessary to recognise that the environment in which we learn shifts and changes due to the nature of the District Nursing role. Thus in teaching the SPQDN Practice Teachers and mentors can employ a learning plan to support this development. The working environment may then be adapted in order to initiate, facilitate and evaluate clinical learning in partnership with the theoretical learning that takes place within higher education.

Understanding the learning plan is an important aspect of education for Practice Teachers and mentors to promote successful learning opportunities. Both the terms learning plan and learning contract are employed interchangeably within learning practice yet can be viewed as one in the same. Commonly a contract is devised between two people in order to set learning aims and objectives enabling outcomes to be achieved (Fry, Ketteridge and Marshall 2009). However, SPQDN students may view the word 'contract' as negative or intimidating term, creating the idea that specific targets have to be met within a specific timescale. This can create additional pressures for learners. However frequently achievement of specialist practice outcomes must be achieved while on the NMC (2001) approved educational programmes. Often this must be done within timescales as a short as only 40 weeks in some HEl's, subsequently some students report that they prefer the use of the term plan as opposed to contract. A plan is not a contract in the legal sense but a professional agreement that can be viewed more positively suggesting progression, a vital milestone for many in making the transition from community staff nurse to that of qualified District Nurse.

\section{How the plan may be employed:}

Establishing a learning plan with an SPQDN student ensuring it is specific to their personal identified learning needs, which meets both the NMC standards (2001) and possibly The Voluntary Standards for District Nurse Education and Practice (QNI 2015c) through discussion and interaction is a crucial element of the Practice Teacher or mentor's role. It is key that all elements of community practice are incorporated into the plan, such as learning in particular patient's homes, and related pedagogical 
discussion, which often happens in the office or car following an episode of care. These discussions and reflections are frequently undertaken after patient interactions or nursing interventions whilst in transit creating further opportunities for learning. This initial interaction according to Gopee (2011) increases the probability of retention by those learning as information increases knowledge and discussion can deepen the learning experience. Hence identifying through discussion, changes within the District Nursing role and recognising the importance of these changes in the context of practice is enabled.

The face of the NHS must change to reflect a model of wellness and health promotion, subsequently nursing as a profession is changing and District Nurses are required to evolve to meet the challenges of the future NHS (NHS England, 2014). In recent years the role of the DN has evolved, no longer is the focus upon just nursing those who are sick but a more proactive stance as a public health leader is required. Addressing health inequalities, disease prevention, promoting independence and well-being are just a few aspects of the SPQDN's diverse role undertaken in partnership with many other members of the multidisciplinary team. To ensure this is incorporated within the learning plan there should be constant interaction with other clinical, non-clinical and non-NHS services. This supports and encourages continued sharing of knowledge enabling further varied experience and opportunities for mutual learning. This in-turn promotes confidence, encouraging the student to work to a higher level of critical thinking reducing negative feelings of exposure, and encouraging inter professional working, a vital element of the SPQDN role.

According to Bastable (2014) learning contracts or plans are an essential element of nurse education. If a structured learning plan is constructed and employed by the Practice Teacher or mentor in partnership, the SPQDN student is supported to achieve intended learning outcomes. Open communication assists in developing an effective working relationship, one where the student is able to relay experiences back through discussion linking theory to practice. Practice teachers can employ skills such as motivational interviewing to encourage student to identify their own learning needs and seek at their own opportunities, the journey of which can be documented on the learning plan. A plan negotiated between student and teacher is more likely to have a positive outcome as it is specific to the students learning needs. Joint planning according to Knowles (1998) ensures that the plan is achievable within set time frames which in-turn can increase motivation which is a key factor to successful learning. The clinical environments must therefore function as an effective learning setting (Gopee, 2010). Clinics, general practices and treatment rooms in addition to bespoke placements are all areas of interest to SPQDN students and will further enhance existing knowledge and skills. Subsequently creating positive learning outcomes and the ability to produce good evidence to support 
learning if the opportunity is recognised. These learning experiences and evidence of these must be relevant and in accordance with the Nursing and Midwifery Council's; Standards to Support Learning and Assessment in Practice (NMC 2006). Each of these opportunities can be planned and structured employing the learning plan. As many SPQDN courses range from 40-52 week's effective time management is key to achieving the vast amounts of knowledge development required to fulfil this highly complex role.

\section{The Practice Teacher or mentor and student relationship:}

A good working relationship according to Anderson, Bould and Sampson (1996) is one of great importance, one where both the student and the teacher can develop a mutual respect for each other. It is a reciprocal learning process that creates an understanding of the other person's values and beliefs within the roles they fulfil. Questioning between the student and teacher becomes a natural part of the everyday learning, providing a deeper learning experience which will serve to improve quality in clinical practice. Recording these episodes within the learning plan can be useful to the students in triggering reflections after learning episodes have taken place. Facilitation of learning is further enhanced by encouraging the student to take responsibility to perform their own SWOT analysis, a SWOT analysis will enable the SPQDN student to identify personal strengths, weaknesses opportunities and threats, assisting with the early stage planning of learning on the SPQDN journey. In practice the SWOT analysis tool can be used to identify an SPQDN students individual learning needs which may be clinically focused, for example wound care or leg ulcer management but may also be more transformational in nature, such as leadership and innovation within community nursing teams. In addition, recognition of potential threats that could ultimately impact on the learning process helping to identify further active intervention. A timely and thorough SWOT analysis can assist in developing a good relationship between the Practice Teacher or mentor and SPQDN student from the onset as a greater understanding seen through the students own personal lens is offered. Burnard (1988) supports self-evaluation, acknowledging it assists learners in identifying personal progress and clarifying what is still to be learned. Reece and Walker (1997) highlighted that as learners in a professional role there is a great deal of personal autonomy. This is particularly pertinent to District Nurses who work autonomously and alone for the majority of the time. Together with personal and professional accountability, appropriate guidance and support from the Practice Teacher or mentor threats can be reduced, enhancing progress developing confidences and competencies in line with NMC's; The Code (2015).

The Mnemonic SMART may be adapted to assist both the student and Practice Teacher or mentor to formulate a direction and incorporate learning objectives and needs. A clear focus is vital in order to 
support the student in meeting the competencies for specialist education and practice. The tool was initially developed within the business world, however some years ago Doran (1981) identified that it can be successfully adapted within the nursing profession. Some years on the principles of SMART have stood the test of time and are still used within contemporary teaching practice. Utilising this mnemonic ensures that the plan is specific, measurable, achievable, realistic and timely. However, within District Nursing practice the demands of the role and constraints within the service such as busy and frequently unquantifiable caseloads, dynamics within the team and complex clinical care situations impact on the timescales associated with evaluating the plan. It is therefore advisable to instil periodic evaluation enabling it to be adapted accordingly, this encourages the learner to identify and discuss their own ongoing learning needs and together aim for a more structured direction.

\section{Reflective practice as a learning tool:}

Knowledge about different reflective models that support SPQDN practice and assist students are arguably an essential element of educational development and should be encouraged by practice teachers (Ciliska, 2005). Johns (2006) model is described as structured and comprehensive, in contrast Gibbs (1988) cycle of reflection may be viewed as a more simplistic process and considered more user friendly by some students. However, it is recognised that individuals will have personal preferences and choose a model personally appropriate considering both the positive and negative elements of each. Gibbs (1988) highlighted writing down open and honest feelings helps students to make sense of certain situations as a useful exercise for some learners and practitioners. This may be particularly pertinent for the SPQDN student who is required to learn and develop in emotive and complex emotional situations. Such as nursing in end of life care, technically complex care episodes such as the care of intravenous lines or complex situations that require leadership and focus when leading teams of community nursing staff through the ever charging world of the NHS. It is through this journey of self- reflection that theory and practice can be linked by exploring what was good and bad, reflecting on what things could or should have been done better. Acknowledging what has gone well and not so well allows the student to learn from their experiences, re-examine, evaluate and recognise the need to further develop identifying further scope for development and improvement.

\section{Supporting students to incorporate evidence based practice:}

Changes within community learning has been a topic open to discussion, Birenbaum (2006) identified that with the complexity of an ever changing society the focus from transmitting isolated knowledge and skills to one of acquiring and sharing more complex competencies, in-turn assists the learner in developing new skills within what is now recognised as a diverse society. Health needs assessments is 
an identified tool that assists practitioners in exploration, identification and prioritisation of health needs within population and community groups (NICE, 2005). Undertaking health needs assessment requires a higher level of judgement and application of current policies and procedures to the clinical environment. This process of learning encourages a more in-depth understanding of requirements to function at a higher level with a deeper and broader method of critical thinking when delivering care in community practice. Proficiency in all aspects of assessment develops a greater understanding of how the SPQDN role is valued and integrated. Having access to individuals within their own home, places District Nurses in a prime position in the provision of health promotion and education initiatives, all relevant and evidence based (NICE, 2005). Frequently SPQDN student report that they struggle to bridge the theory practice gap. The learning plan can be employed to structure the student's ability to progress from simply applying the evidence base to their own clinical practice to the wider role of disseminating good practice to peers and subordinates and furthering critical discussion at organisational level and beyond, often a daily part of the SPQDN's practice.

The focus of evidence-based practice (EBP) is integral within District and community nursing. Baurmann (2010) identified that this process alone does not increase learner's confidences in the ability to apply EBP. Developing knowledge and skills within practice also requires adjustment in attitudes and beliefs, thus designing learning to promote self-efficacy. Self-efficacy determines how the student feels, thinks and motivates oneself. Self-appraisal enhances accomplishment as the learner recognises that a strong sense of efficacy enables them to look at complex situation within practice as challenging rather than a threat. This increases the likelihood of a more positive outcomes again promoting progression along the SPQDN learning journey.

According to Benner (2001) as professionals, the journey of learning is lifelong due to continuous changes in the individual coupled with changes within nursing in general and the District Nursing service in particular. The SPQDN student may be identified as the novice within this specialist field of nursing practice however having prior life, nursing or educational experience assists in moving him or her to a level of competent practitioner. These experiences can be acknowledged and documented on the learning contract or plan and this may make the student feel valued for the experiences they bring to the role. The teacher is seen as the expert as they may transfer knowledge and skills relating to the decision making process at times but at other times the teacher acts as enabler to the student in finding their own way through self-directed learning. Frequently for the expert District Nurse an instinct known as intuitive process assists in nursing practice. This is drawn from the District Nurses tacit knowledge and experience as well as theoretical tennets. The knowledge of understanding the actions taken and why is sometimes difficult to articulate therefore requires exploration. To 
acknowledge that every situation is different and develop application in practice to enable opportunities for independent thought and decision making. Whilst acknowledging that as professional autonomous practitioners are accountable and must ensure all practice and decisions made around us work within our own scope of practice confidently and competently and in accordance with the NMC's; The Code (2015).

\section{Clarity of roles:}

Clarity of roles and responsibilities in the learning process assists the learner to understand and acknowledge that as nurses we are adult learners and are responsible for our own learning development and ultimately competent practice. As adult learners it is important to recognise the process of planning is the first step to facilitating effective learning. It is recognised that a relationship is established at the beginning and develops keeping the learner engaged and Practice Teacher or mentor throughout the process. Revisiting the process is an important factor as it is assists in recognising constraints within practice that may ultimately impact on learning. Encouraging and negotiating ensures competencies are met through on-going self-evaluation and self-reflection further encouraging an eagerness to continue personal and professional development. This in-turn prepares students to work to a higher level, recognising that nursing is lifelong learning, and the planning enables progression in practice. Development of educators is a requirement as teaching is incorporated in all aspects of District Nursing Practice at all levels. This is reliant upon the preparation of safe efficient effective practitioners preparing to enter the register at a higher level in accordance with NMC (2001).

\section{In conclusion:}

Learning contracts or plans can be flexible and accommodate the individual needs of learners within the complex and highly specialist world of District Nursing practice. They provide a tool to incorporate evidence based practice, clarify roles and responsibilities of the teacher and learner and may help both parties to ensure continued focus within established time frames in the development of competence ensuring progression to registration as a community specialist practioner. The use of the learning plan is a helpful tool for Practice Teachers, mentors and SPQDN students in ensuring a quality learning experience, which prepares students for the ever-evolving nature of District Nursing practice.

\section{Reflective questions:}


1. Do you currently use learning plans in your teaching practice, if so what works well at present and why?

2. Reflect on a time when you may have been able to benefit from the employment of a learning plan to guide a student, perhaps in managing time scales or agreeing on appropriate learning goals.

3. Can you identify a way to share your reflections on this article with your own nursing team to promote further opportunities for learning and development?

Anderson, G., Bould, D. and Sampson, J. (1996) Learning Contracts; A Practical Guide. Routledge, London.

Bastable, S.B. (2014) Nurse as Educator. Principles of Teaching and Learning for Nursing. Practice. $4^{\text {th }}$ Ed, Jones \& Bartlett Learning, Burlington.

Baurmann, S.L. (2010) The limitations of evidence based Practice. Nurse Science 23 (3) 226-30.

Benner, P. (2001) From novice to expert: Excellence and power in clinical nursing practice. New Prentice Hall Inc, New Jersey.

Birenbaum, M. (2006) EARLI position paper. A learning integrated assessment system. Educational Research Review. 1, 61-7.

Ciliska, D. (2005) Educating for evidence based practice. Journal of Professional Nursing. 21 (6) 345350.

Cook, C. (2010). The future of nursing begins at home. British Journal of Nursing. 15(4) 188.

Department of Health (2013) The Education Outcomes Framework, London, Her Majesty's Stationary Office.

Doran, G. T. (1981) There's a S.M.A.R.T. way to write management goals and objectives. Management Review. 70 (11) AMA Forum. 35-6.

Francis, R. (2013) Mid Staffordshire NHS Foundation Trust Public Enquiry: final report. Doi: http://webarchive.nationalarchives.gov.uk/20150407084231/http://www.midstaffspublicinquiry.co m/report (17 October 2017).

Fry, H., Ketteridge, S. and Marshall, S. (2010) A Handbook for Teaching and Learning in Higher Education. $3^{\text {rd }}$ Ed. Routledge, London.

Gibbs, G. (1988) Learning by doing: A guide to teaching \& learning methods. Further education Unit, Oxford Polytechnic, Oxford.

Gopee, N. (2010). Practice Teaching in Healthcare. Sage Publications, London.

Gopee, N. (2011) Mentoring and Supervision in Healthcare. Sage Publications, London.

Johns, C. (2006) Engaging reflection in practice: A narrative approach. Blackwell publishing Ltd, Oxford. 
Keogh, B. (2013) Review into the quality of care and treatment provided by 14 hospital trusts in England: overview report. Doi: http://www.nhs.uk/nhsengland/bruce-keoghreview/documents/outcomes/keogh-review-final-report.pdf (October 2017).

Lepper, J. (2010) Professional nursing as a degree profession, GP Magazine, Jan 18, 36.

National Health Service (2014) Five Year Forward View. Doi: https://www.england.nhs.uk/wpcontent/uploads/2014/10/5yfv-web.pdf (accessed 16 October 2017).

National Institute for Health and Care Excellence (2005) Health needs assessment: A practical guide. NICE.

Nursing and Midwifery Council (2001) Standards for Specialist Education and Practice. NMC, London. Nursing and Midwifery Council (2006) Standards to Support Learning and Assessment in Practice. NMC, London

Nursing and Midwifery Council (2015) The Code. NMC, London.

The Royal College of Nursing on behalf of the independent Willis Commission on Nursing Education (2012) Quality with compassion; the future of nursing education, London: Royal College of Nursing.

The Queens Nursing Institute (2015a) The Value of the District Nurse Specialist Practioner Qualification. QNI, London.

The Queens Nursing Institute (2015b) report on District Nurse education 2015-16. QNI, London.

The Queens Nursing Institute and The Queens Nursing Institute Scotland (2015c) The QNI/QNIS Voluntary Standards for District Nurse Education and Practice. QNI, London. 